\title{
Modular Pd/Zeolite Composites Demonstrating the Key Role of Support Hydrophobic/Hydrophilic Character in Methane Catalytic Combustion
}

\author{
Pit Losch, ${ }^{\mathrm{a}, \mathrm{b}}$ Weixin Huang, ${ }^{\mathrm{a}}$ Olena Vozniuk, ${ }^{\mathrm{b}}$ Emmett Goodman, ${ }^{\mathrm{a}}$ Wolfgang Schmidt, ${ }^{\mathrm{b}}$ \\ Matteo Cargnello a*
}

*Corresponding author email: $\underline{\text { mcargnello@stanford.edu }}$

a Department of Chemical Engineering and SUNCAT Center for Interface Science and Catalysis, Stanford University, Stanford, California 94304, United States

b Department of Heterogeneous Catalysis, Max-Planck-Institut für Kohlenforschung, KaiserWilhelm-Platz 1, Mülheim an der Ruhr, Germany, 45470 


\section{Supplementary Tables}

Table S1. Developed supports with varying hydrophobicity.

\begin{tabular}{|c|c|c|c|c|c|c|}
\hline & $\mathbf{S i} / \mathbf{A l}^{\mathbf{a}}$ & $\begin{array}{c}\text { Sapp. BET }_{\text {Bet }} / \\
\mathbf{m}^{2} \mathbf{g}^{-1 \mathbf{b}}\end{array}$ & $\begin{array}{c}V_{\text {micro }} / \\
\mathbf{c m}^{3} \mathbf{g}^{-1} \mathbf{b}\end{array}$ & $\begin{array}{c}V_{\text {meso }} / \\
\mathbf{c m}^{3} \mathbf{g}^{-1 \mathbf{b}}\end{array}$ & $\begin{array}{c}\text { Water Uptake / } \\
\text { mmol g(support) }{ }^{-1} \mathrm{c}\end{array}$ & $\begin{array}{c}\mathbf{H}_{2} \mathrm{O} \text {-uptake / } \\
\text { Molecule } \mathbf{n m}^{-3}\end{array}$ \\
\hline$\gamma-\mathrm{Al}_{2} \mathrm{O}_{3}$ & 0 & 98 & 0.004 & $0.84^{\mathrm{d}}$ & 1.32 & 0.9 \\
\hline $\mathrm{m}-\mathrm{Al}_{2} \mathrm{O}_{3}$ & 0 & 214 & 0.005 & $0.25^{\mathrm{e}}$ & 1.70 & 3.9 \\
\hline \multirow[t]{4}{*}{$\mathrm{m}-\mathrm{ZSM}-5^{\mathrm{f}}$} & 12.5 & 387 & 0.11 & 0.11 & 2.85 & 7.8 \\
\hline & 25 & 417 & 0.11 & 0.18 & 1.88 & 3.9 \\
\hline & 40 & 526 & 0.10 & 0.2 & 1.49 & 3.0 \\
\hline & $>300$ & 483 & 0.09 & 0.24 & 1.07 & 1.9 \\
\hline $\mathrm{m}-\mathrm{MOR}^{\mathrm{f}}$ & 10 & 386 & 0.18 & 0.08 & 4.67 & 10.8 \\
\hline \multirow[t]{4}{*}{$m-B{ }^{f}$} & 13 & 625 & 0.17 & 0.28 & 0.92 & 1.2 \\
\hline & 19 & 718 & 0.14 & 0.33 & 0.88 & 1.1 \\
\hline & 40 & 827 & 0.11 & 0.65 & 0.73 & 0.6 \\
\hline & $>300$ & 715 & 0.07 & 0.63 & 0.36 & 0.3 \\
\hline \multirow[t]{5}{*}{$\mathrm{m}-(\mathrm{US}) \mathrm{Y}^{\mathrm{f}}$} & 2.5 & 674 & 0.20 & 0.1 & 4.99 & 10 \\
\hline & 6 & 617 & 0.25 & 0.15 & 3.24 & 4.9 \\
\hline & 15 & 874 & 0.16 & 0.45 & 1.26 & 1.3 \\
\hline & 40 & 830 & 0.07 & 0.85 & 0.55 & 0.4 \\
\hline & $>300$ & 720 & 0.05 & 0.52 & 0.44 & 0.5 \\
\hline KIT-6 ${ }^{f}$ & $\infty$ & 508 & 0.06 & 0.28 & 0.11 & 0.2 \\
\hline
\end{tabular}

a: Based on supplier's information and confirmed by XPS analyses.

b: Nitrogen physisorption analysed by BET, t plot and DFT pore size methods.

c: water uptake measurements were performed at $100{ }^{\circ} \mathrm{C}$.

d: Pore diameters for $\gamma-\mathrm{Al}_{2} \mathrm{O}_{3}$ extend over a range from 10 to 50 with a maximum at $35 \mathrm{~nm}$.

e: Pore diameter of meso- $\mathrm{Al}_{2} \mathrm{O}_{3}$ of $4-6 \mathrm{~nm}$.

f: All the prepared mesostructured samples exhibited mesopore diameters of $4-6 \mathrm{~nm}$ 
Table S2. CO chemisorption data for selected samples with $0.1 \mathrm{wt} \%$ of $3.2 \mathrm{~nm} \mathrm{Pd}$ nanoparticles. With the assumption of spherical nanoparticles a maximum Accessible surface area of Palladium of $0.20 \mathrm{~m}^{2} \mathrm{~g}^{-1}$ can be expected.

\begin{tabular}{|c|c|c|c|}
\hline Entry & Sample & $\begin{array}{c}\text { Accessible Pd area / } \\
\mathbf{m}^{\mathbf{2}} \mathbf{g}^{-\mathbf{1}}\end{array}$ & $\begin{array}{c}\text { Dispersion / } \\
\mathbf{\%}\end{array}$ \\
\hline 1 & $0.1 \mathrm{wt} . \% \mathrm{Pd}(3.2 \mathrm{~nm}) / \gamma-\mathrm{Al}_{2} \mathrm{O}_{3}$ & 0.13 & 32 \\
\hline 2 & $0.1 \mathrm{wt} \% \mathrm{Pd}(3.2 \mathrm{~nm}) / \mathrm{m}-\mathrm{ZSM}-5(40)$ & 0.09 & 20 \\
\hline 3 & $0.1 \mathrm{wt} \% \mathrm{Pd}(3.2 \mathrm{~nm}) / \mathrm{m}-\mathrm{Beta}(40)$ & 0.16 & 36 \\
\hline 4 & $0.1 \mathrm{wt} \% \mathrm{Pd}(3.2 \mathrm{~nm}) / \mathrm{m}-\mathrm{USY}(40)$ & 0.12 & 27 \\
\hline
\end{tabular}




\section{Supplementary Figures}
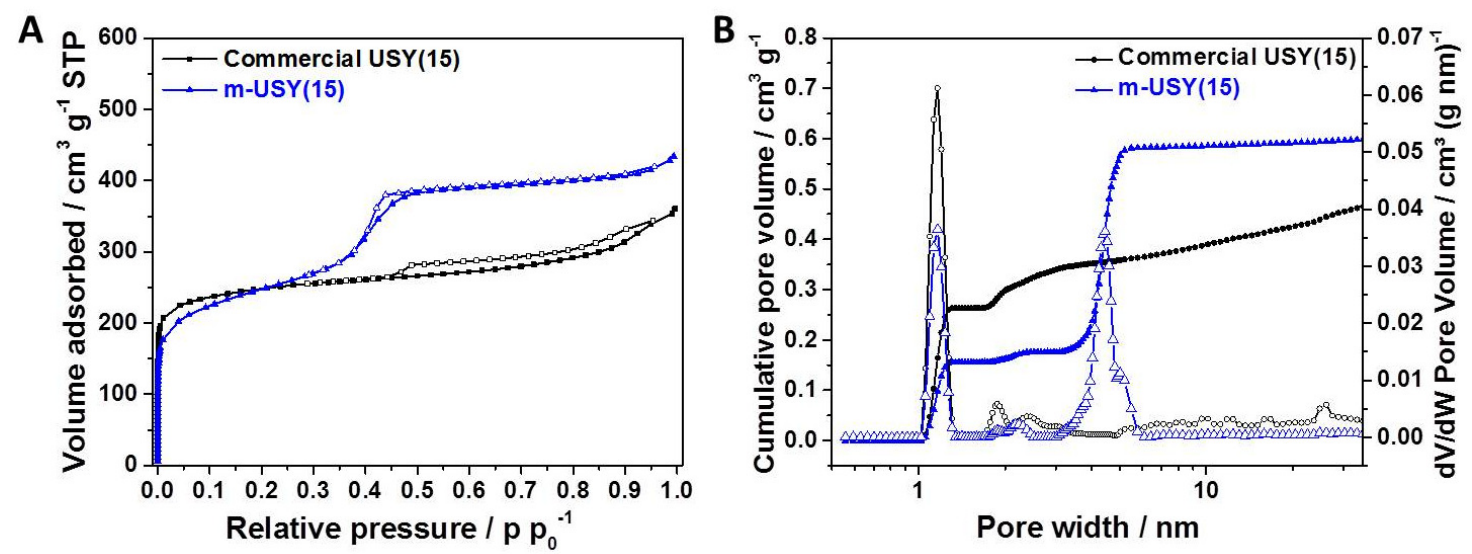

Figure S1. A) N2-physisorption isotherm and B) DFT pore size distribution for H-USY(15). 

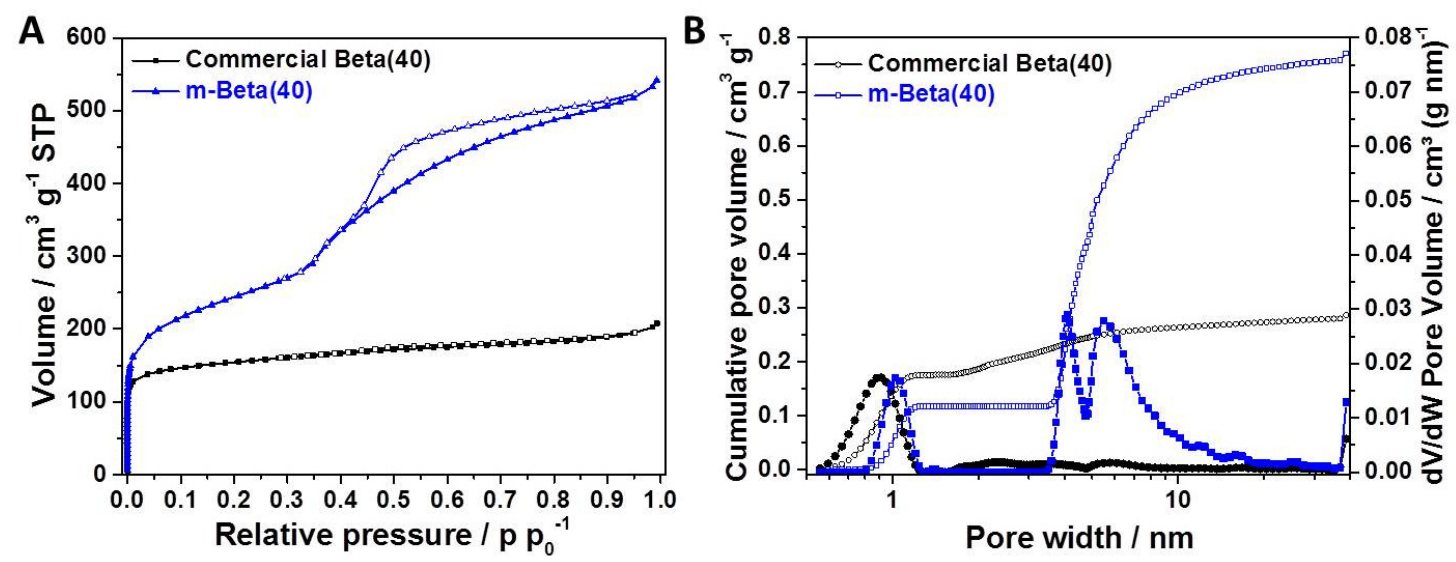

Figure S2. A) $\mathrm{N}_{2}$-physisorption isotherm and B) DFT pore size distribution for H-Beta(40). 


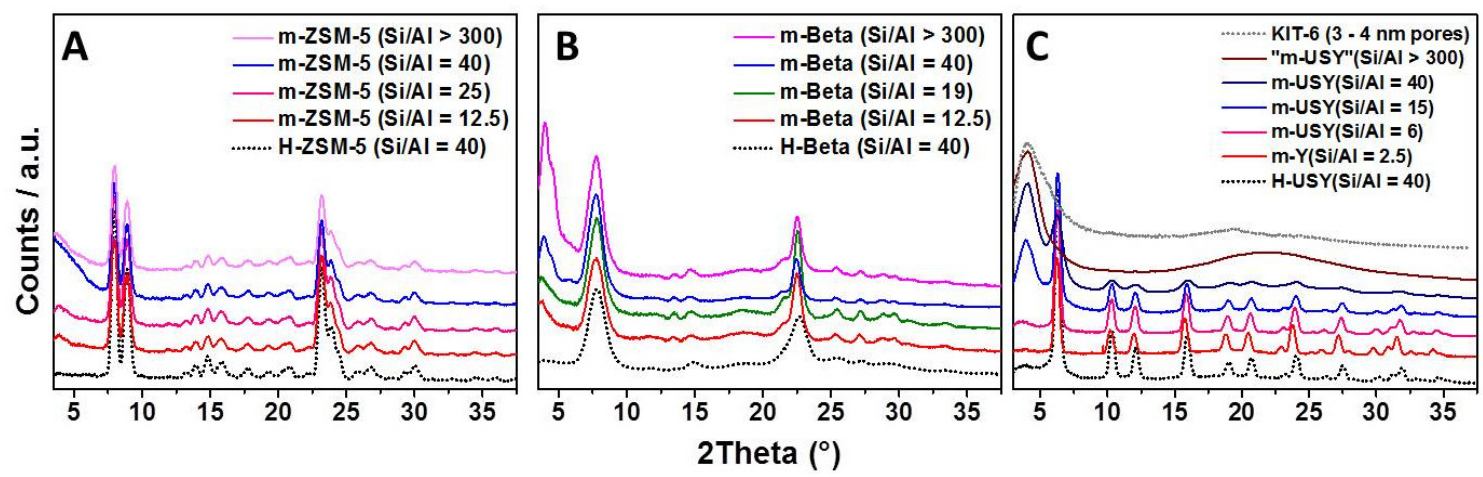

Figure S3. Powder X-ray diffraction patterns of all the prepared mesostructured supports. A) ZSM-5; B) Beta and C) USY zeolites. 


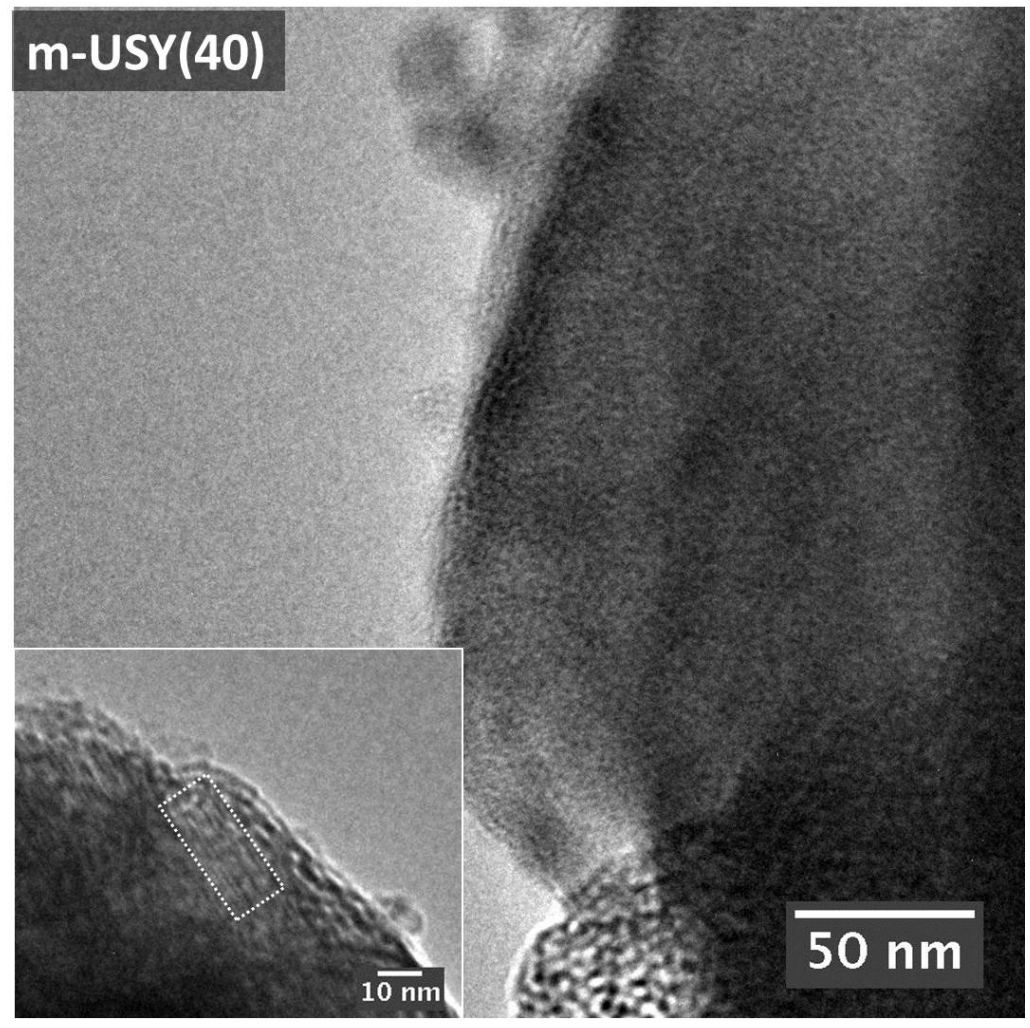

Figure S4. Successful synthesis of silicon rich meso-USY(40). Main figure shows generation of ordered mesoporosity. Insert, at a higher magnification, shows intact lattice fringes of zeolite USY(40). 


\section{5 wt \% Ru(2.6 nm) / m-USY(15)}
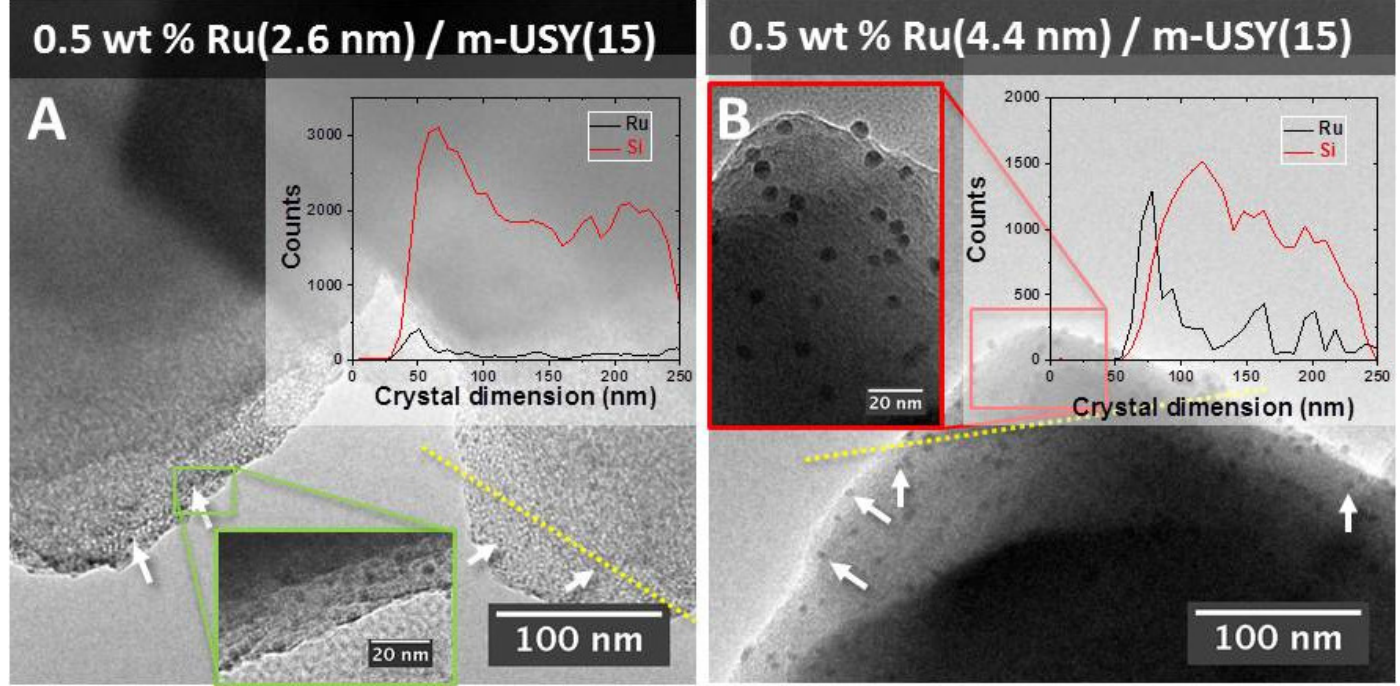

Figure S5. Ru nanoparticles of different diameters deposited on m-H-USY(15) zeolite. A) $\mathrm{Ru}(2.6 \mathrm{~nm})$; B) $\mathrm{Ru}(4.4 \mathrm{~nm})$. Red and green insert are larger magnifications at zeolite edges. Yellow lines indicate EDX line scans recorded for the two different materials plotted in the respective inserts. Note: EDX line scans are measured through the whole zeolite grains. 


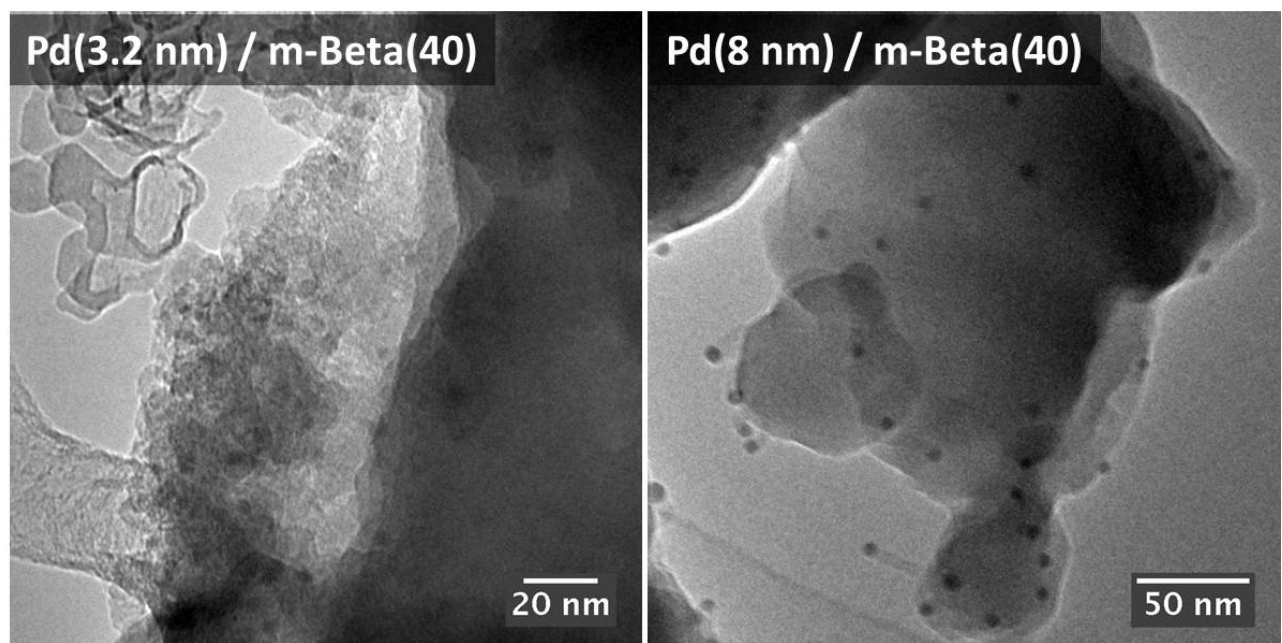

Figure S6. Pd particles of different sizes loaded onto m-Beta(40). With $8 \mathrm{~nm}$ Pd particles are clearly seen on the edges and outer surface of the zeolite. 

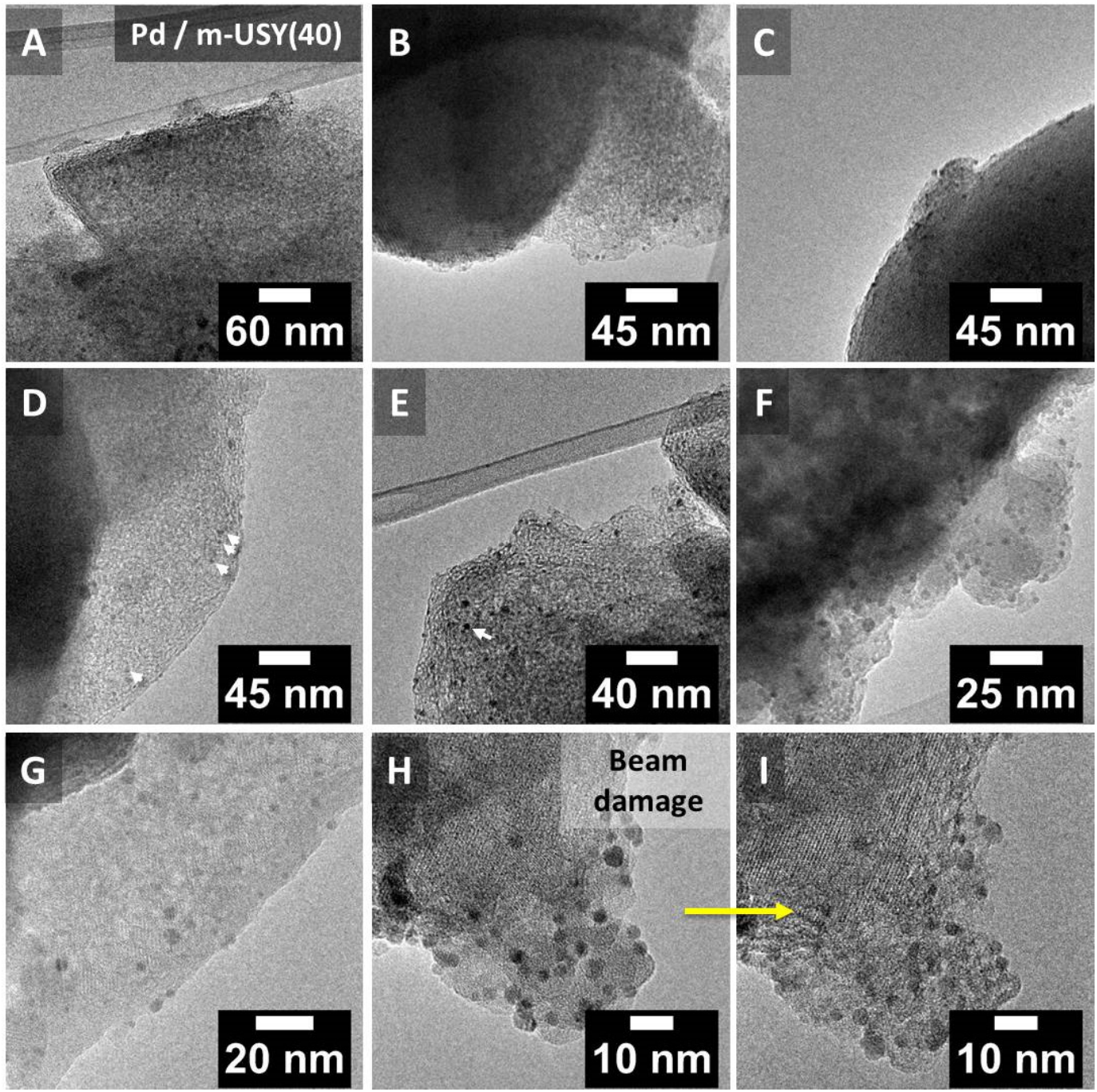

Figure S7. TEM micrographs at different magnifications of the $0.1 \mathrm{wt} \% \operatorname{Pd}(3.2 \mathrm{~nm}) / \mathrm{m}$ USY catalyst. A, B, C, D and E) show the mesostructured zeolite without a significant amount of $\mathrm{Pd}$ nanoparticles on the zeolite grain edges. F and G) present $\mathrm{Pd}$ nanoparticles deposited on mesoporous zeolite. $\mathrm{H}$ and I) indicate that high magnification micrographs are not trivial to obtain for these insulating supports and we generally observed severe beam damage i.e. nanoparticle sintering and collapsing of alumino siliceous frameworks. 

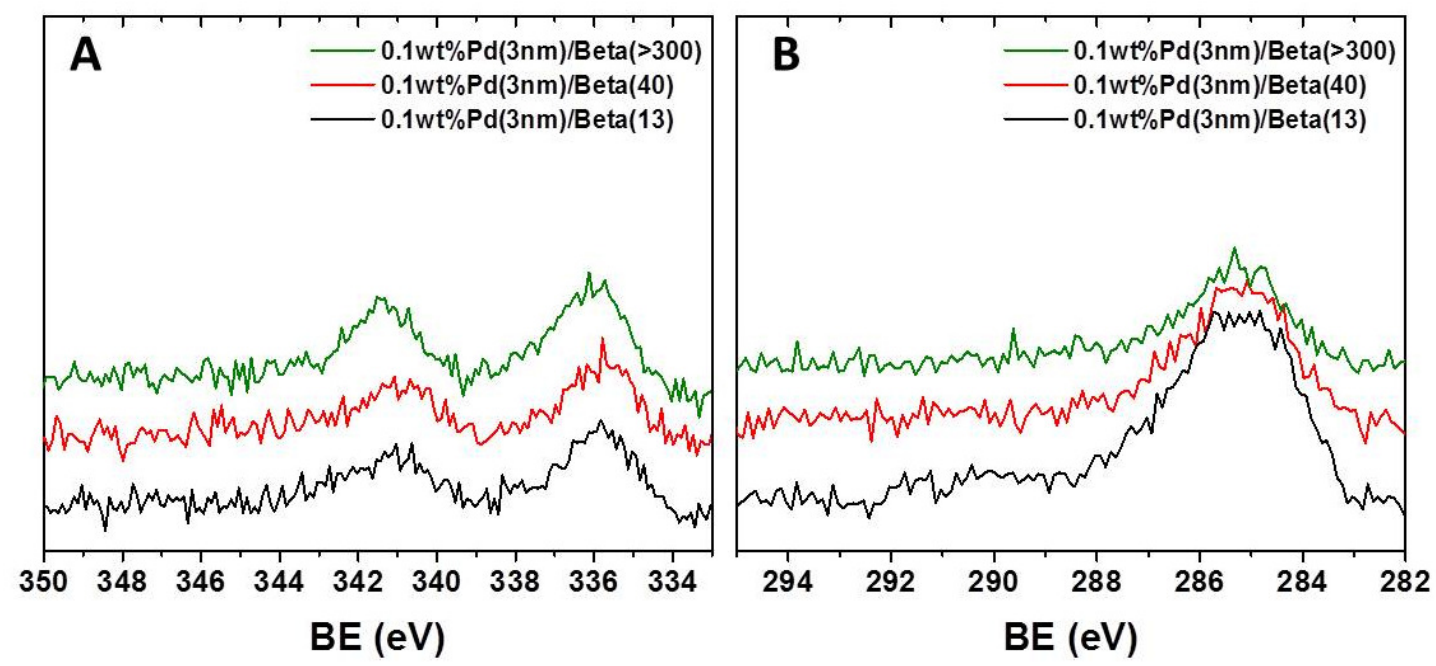

Figure S8. XPS spectra for samples with Pd particles on a series of Beta zeolite supports with different $\mathrm{Si} / \mathrm{Al}$ ratios. A) $\mathrm{Pd}-3 \mathrm{~d}_{5 / 2}$ signals show the presence of a significant fraction of $\mathrm{PdO}$ $(336.7 \mathrm{eV})$ already before catalysis; B) C-1s calibration of the signals at $284.8 \mathrm{eV}$. 

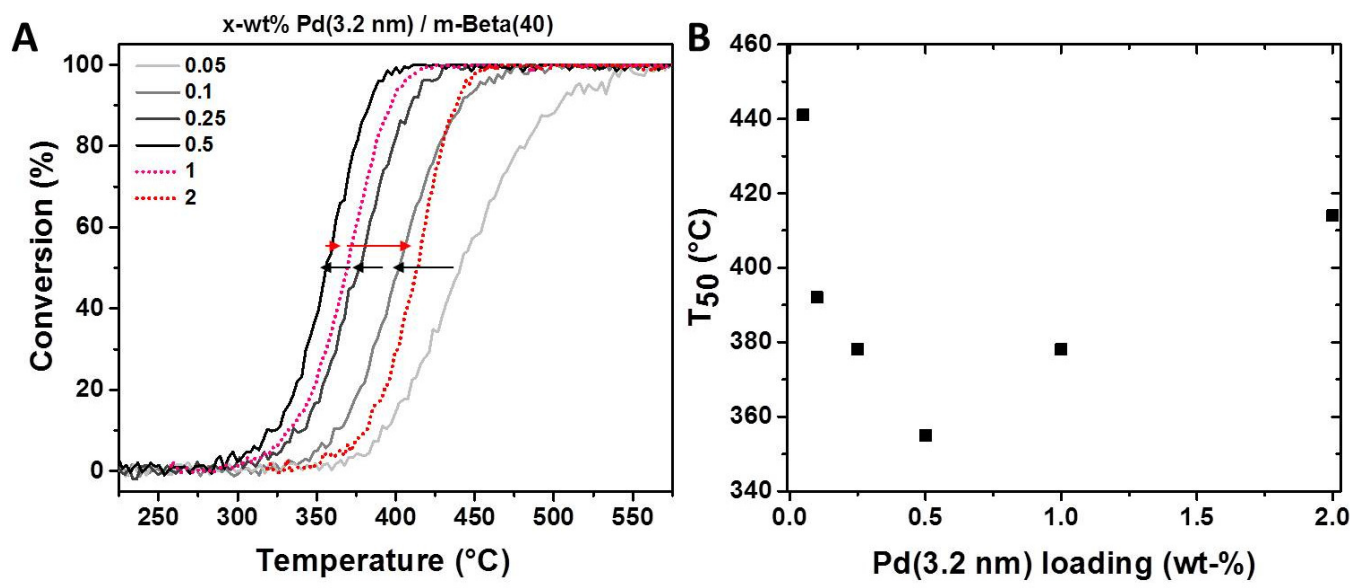

Figure S9. Optimization of Pd loading: A) Temperature programmed reactions; B) $\mathrm{T}_{50}$ as a function of Pd loading.

Interestingly, in the case of a 2 wt \% loading in $\mathrm{Pd}$ a sample would have to hold 20 $\mathrm{mg}(\mathrm{Pd}) / 1 \mathrm{~g}($ zeolite $)=0.00167 \mathrm{~cm}^{3}(\mathrm{Pd})$ (with a density of Pd of $12 \mathrm{~g} / \mathrm{cm}^{3}$ ). Such a volume represents only a fraction of the available mesopore volume $\left(>0.1 \mathrm{~cm}^{3}\right.$ in all cases) thus one could expect that Pd should be well dispersible throughout the zeolites even at higher loadings. The fact is that the deposition of colloidal particles onto a support is not a capillarity effect, instead involves specific interactions between particles and support. For this reason, higher loadings are hard to achieve in one step. The exact reasons for this trend may relate to the possibly slow kinetics of the Pd nanoparticle deposition mechanism leading to nonhomogeneous Pd nanoparticle distributions. 

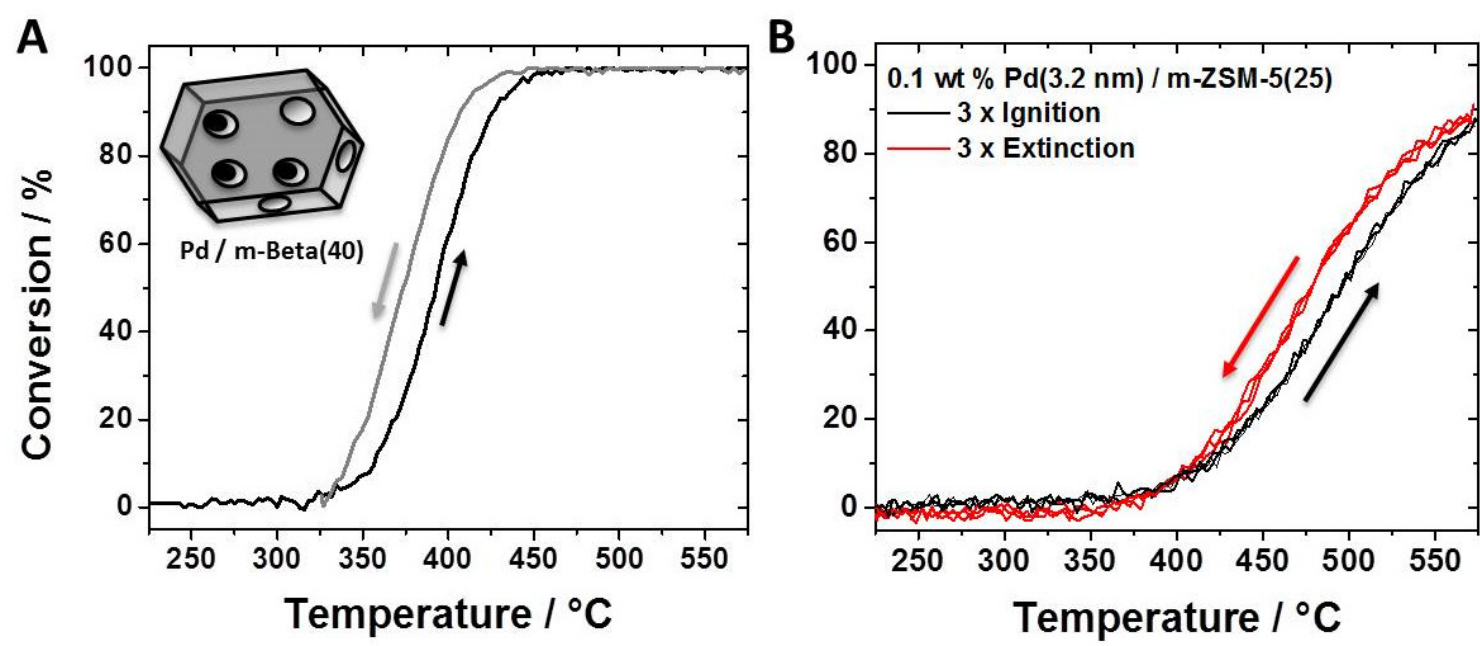

Figure S10. A) Ignition and extinction curve for Pd / m-Beta(40). Hysteresis of $20 \mathrm{~K}$ was observed. B) Three complete ignition-extinction cycles for one exemplary sample proves very high reproducibility of the catalytic setup. 


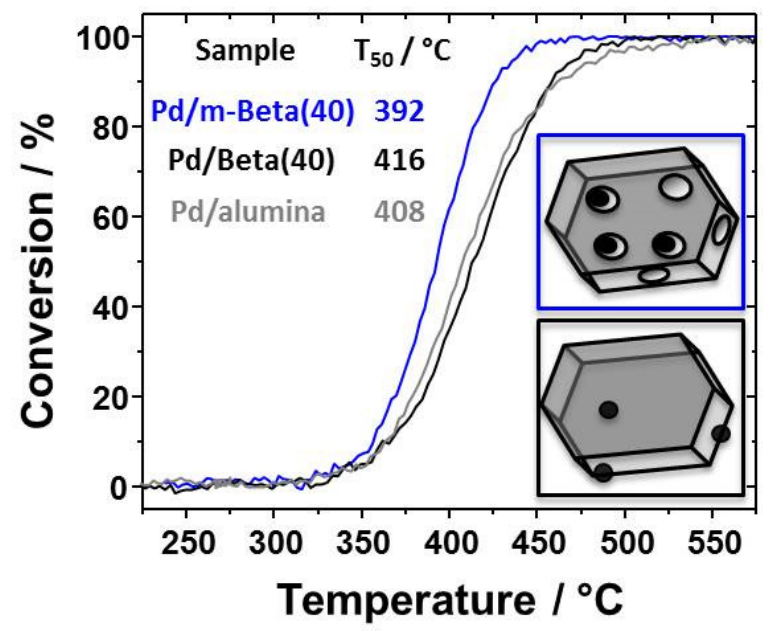

Figure S11. Methane combustion light-off behavior for Pd nanoparticles on mesoporous Beta zeolite (blue) as compared to when it was deposited on microporous starting material (black). A significant difference between the two $\mathrm{T}_{50}$ values was seen. 


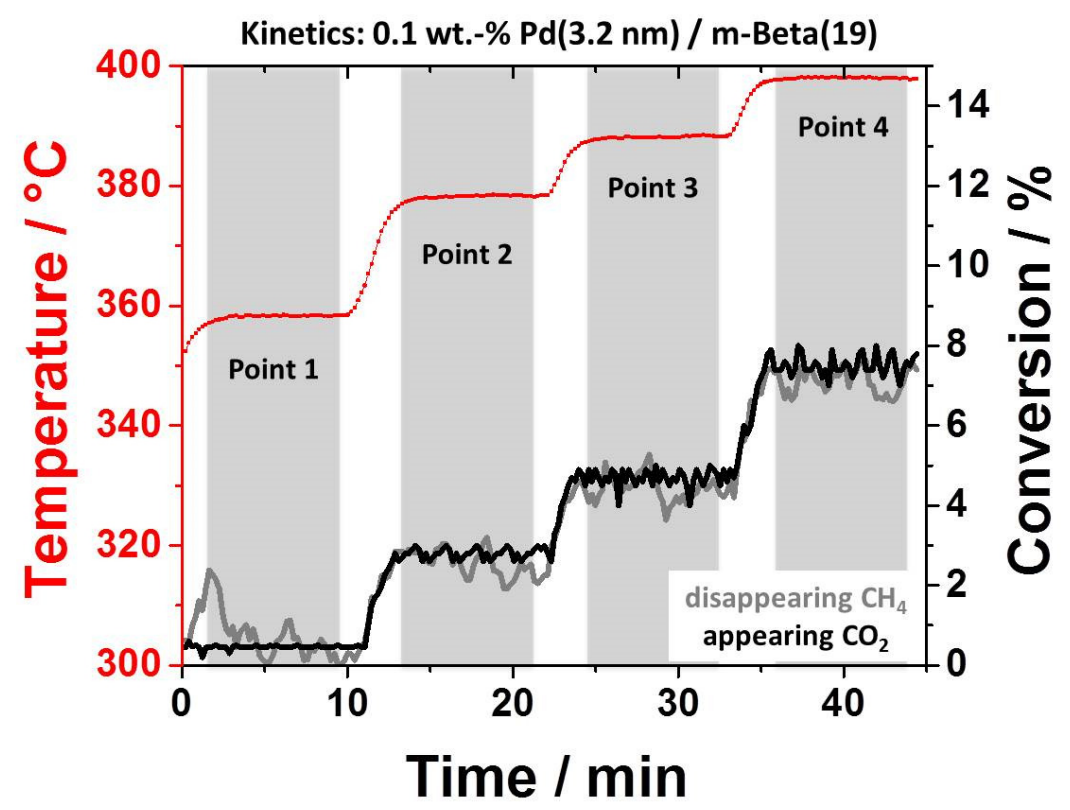

Figure S12. Typical procedure for kinetics data acquisition, ramping to different temperatures controlling conversion( $\mathrm{CO}_{2}$ app.) with conversion( $\mathrm{CH}_{4}$ disapp.). 


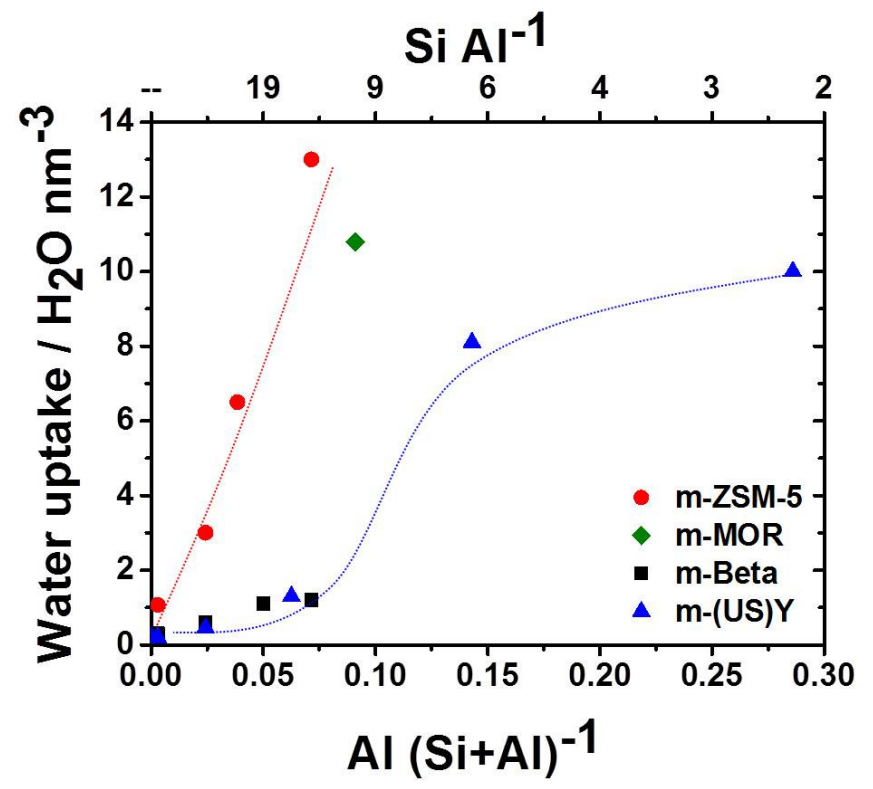

Figure S13. Hydrophilicity expressed in terms of water uptake at $100{ }^{\circ} \mathrm{C}$ in molecules of $\mathrm{H}_{2} \mathrm{O}$ per $\mathrm{nm}^{3}$ of pore volume. Small micropore m-ZSM-5 and m-mordenite zeolites follow a linear trend, the water uptake linearly decreases with lower Al contents. Large micropore m-Beta and m-USY samples also show lower water uptakes with lower Al contents, though not with a strictly linear relation. As discussed in the main text increased vdW potential overlaps between guest molecules and the smaller micropores are responsible for the higher water uptake in small pore zeolite. 

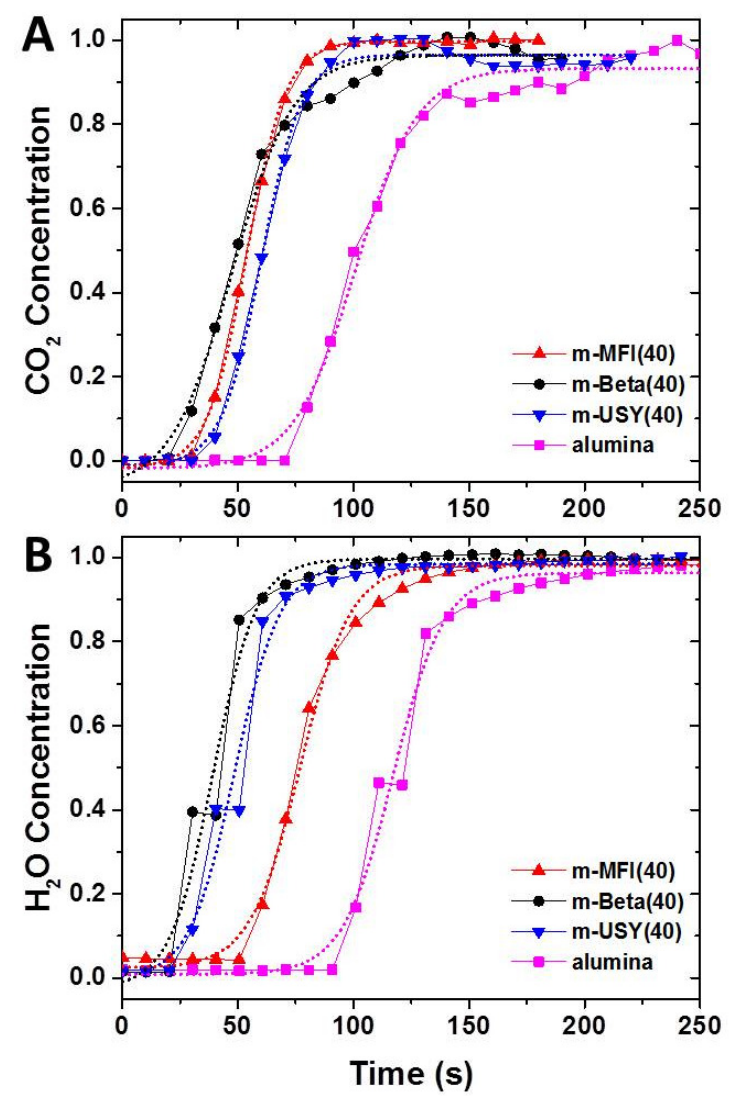

Figure S14. A) $\mathrm{CO}_{2}$ and B) $\mathrm{H}_{2} \mathrm{O}$ breakthrough curves at $350{ }^{\circ} \mathrm{C}$. Concentrations are normalized (200 mg of each material were used with experimental $\mathrm{CO}_{2}$ concentration of 0.4 vol.-\%, respectively a $\mathrm{H}_{2} \mathrm{O}$ concentration of 4.2 vol.- $\%$ in $20 \mathrm{~mL} . \mathrm{min}^{-1} \mathrm{Ar}$ ). 

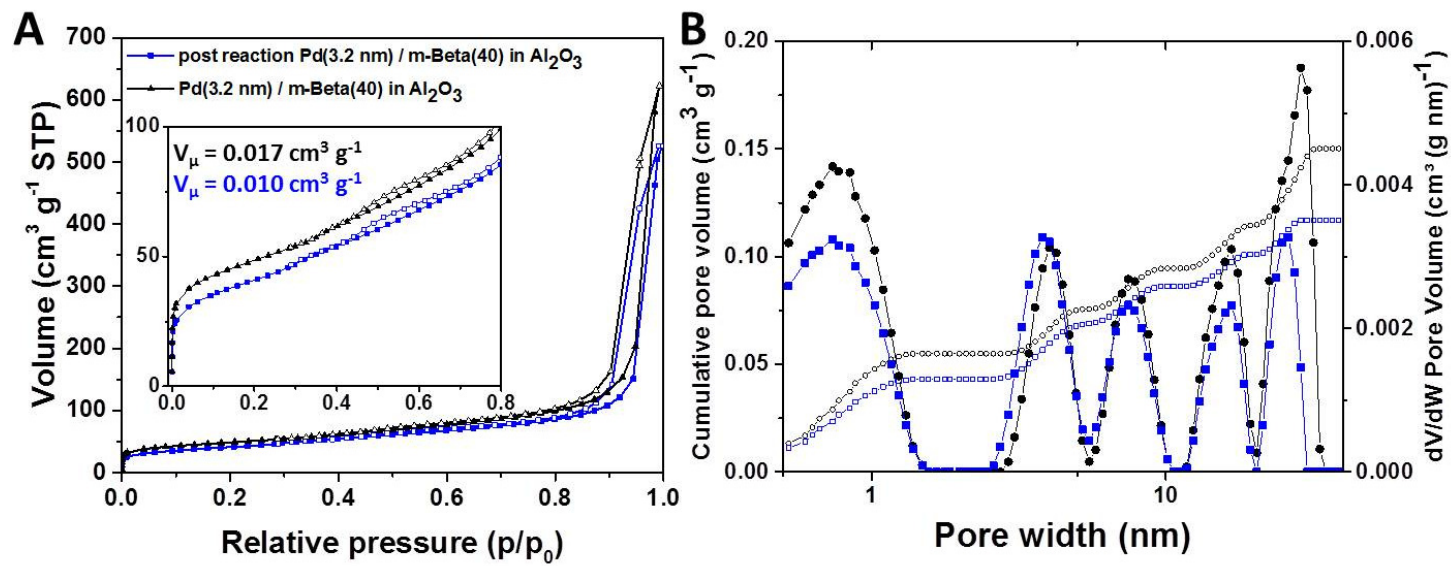

Figure S15. A) $\mathrm{N}_{2}$ physisorption isotherm of a realistic catalytic bed before and after reaction; B) DFT pore size distribution of a $20 \mathrm{mg} \mathrm{Pd}(3.2 \mathrm{~nm}) / \mathrm{m}$-Beta(40) in $180 \mathrm{mg} \gamma$ alumina catalytic bed before and after methane oxidation in the presence of steam. Micro- and mesoporosity (0.7 and $4 \mathrm{~nm})$ remain intact. 


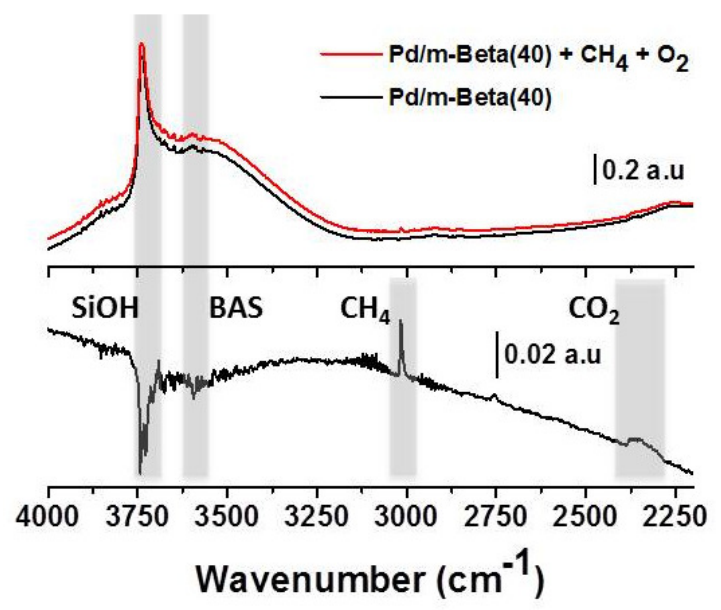

Figure S16. Full range original data for activated $\mathrm{Pd} / \mathrm{m}-\mathrm{Beta}(40)$ and during flowing methane and oxygen. After subtraction, it becomes clear that methane is transformed into $\mathrm{CO}_{2}$ and water which is evacuated by adsorbing to acidic and silanol sites. 